\title{
Original
}

\section{The Effect of Diltiazem and Verapamil on Hepatic Microsomal Drug Metabolizing Enzymes in Rat}

\author{
Eiji Uchida, Norimichi Takahashi, Shinichi Kobayashi, Kenichi KaI, \\ Shigeyuki IIDA, Tatsuhiko Kurato, Kenji Hamada \\ and Hajime YasuHARA
}

\begin{abstract}
Diltiazem and verapamil, calcium channel blocking agents, are reported to elevate plasma concentrations of some clinically used drugs in humans. In the present study, the effect of diltiazem and verapamil on the hepatic mixed function-monoxygenase system was investigated in Sprague-Dawley rats. Diltiazem and verapamil significantly increased cytochrome P-450 content by $60.8 \%(\mathrm{p}<0.01)$ and $51.3 \%(\mathrm{p}<0.01)$, respectively, after 5 days of treatment compared to the control value. Content of cytochrome $b_{5}$ was significantly increased by verapamil $(45.3 \%, \mathrm{p}<0.01)$ but not by diltiazem. Activity of aminopyrine-N-demethylase was significantly increased by 5 days of treatment with diltiazem $(61.9 \%, \mathrm{p}<0.01)$ and verapamil $(47.8 \%, \mathrm{p}<0.01)$. Aniline hydroxylase activity was gradually increased by verapamil treatment with significance on day $5(33.8 \%, \mathrm{p}<0.05)$. The serum ratio of dimethadione to trimethadione (DMO/TMO) was significantly increased by diltiazem (from 0.40 to $0.87, \mathrm{p}<0.05$ ), but not by verapamil treatment. Diltiazem significantly enhanced the amount of 4-hydroxyantipyrine excreted into urine from $8.8 \%$ to $24.5 \%(\mathrm{p}<0.01)$. There was no significant change of any antipyrine metabolite by verapamil treatment. Both diltiazem and verapamil significantly increased the debrisoquine/4-OH debrisoquine ratio indicating inhibition of debrisoquine metabolism. These results suggest that both diltiazem and verapamil induce cytochrome P-450 but have different effects on the activity of P-450 isozyme in rats. Inhibition of hepatic drug-oxidizing enzymes by diltiazem and verapamil reported in humans was observed in this study of the metabolism of debrisoquine in rats.
\end{abstract}

Key words: diltiazem, verapamil, cytochrome P-450, model drugs, rat

\section{Introduction}

Calcium channel blockers are widely accepted for treatment of ischemic heart disease, cardiac arrythmia and hypertension ${ }^{1)}$. Diltiazem and verapamil are prototypes of calcium antagonists and have been used clinically for more than a decade, often in combination with other drugs. Both diltiazem and verapamil are known to be extensively metabolized by drug-oxidizing enzymes in the liver ${ }^{2}$. Recent studies suggest that both diltiazem and verapamil impair the clearance of other drugs in humans; diltiazem was reported to increase AUCs

Department of Pharmacology, Showa University School of Medicine, 1-5-8 Hatanodai, Shinagawa-ku, Tokyo 142, Japan. 
of nifedipine ${ }^{3)}$, propranolol and metoprolol ${ }^{4}$. Diltiazem decreased antipyrine clearance ${ }^{5)}$ but did not change liver blocd flow ${ }^{6}$. Verapamil was reported to increase serum digoxin levels ${ }^{7,8)}$, to decrease antipyrine clearance ${ }^{9,10)}$, and to prolong quinidine half-life ${ }^{11)}$. Verapamil impaired theophylline clearance but diltiazem did not ${ }^{12}$. Although the precise mechanisms of these phenomena are yet to be elucidated, these interactions are thought to be due to inhibition of oxidative drug-metabolizing enzymes in the liver by diltiazem or verapamil. At present few data are available on the activities of hepatic drug-oxidizing enzymes with treatment of diltiazem or verapamil in animals.

In the present study, effects of diltiazem and verapamil on the hepatic mixed-function monoxygenase (P-450) system were investigated in the rat using antipyrine (AP), trimethadione (TMO), and debrisoquine (DB) as model substrates.

\section{Methods}

Animals: Male Sprague-Dawley (SD) rats (200-350 g) were used. Animals were fed laboratory chow and tap water ad libitum until 24 hours before administration of the model drugs. They were then deprived of food but could drink tap water freely for the 24 hours before administration of the model drugs.

Chemicals: Diltiazem hydrochloride was kindly supplied by Tanabe Seiyaku Co., Ltd. and verapamil hydrochloride by Eisai Co., Ltd. AP and its metabolites, 4-hydroxyantipyrine (OHA), 3-hydroxymethylantipyrine (HMA), and norantipyrine (NorA) were purchased from Chikoh Co., Ltd., Tokyo, Japan. TMO (Dainippon Pharmaceutical Co., Ltd.), available commercially as $66.7 \%$ powder was used. DB and 4-hydroxy debrisoquine (4-OHDB) were provided from Nippon Roche K.K., Tokyo, Japan. All other chemicals were reagent grade obtained from commercial sources and used without further purification.

Ex vivo study: Diltiazem hydrochloride $(140 \mathrm{mg} / \mathrm{kg})$ or verapamil hydrochloride $(47.5$ $\mathrm{mg} / \mathrm{kg}$ ) was dissolved in distilled water and administered by gastric intubation at intervals of 12 hours for 1,3 , and 5 days. The control group was given the same volume of distilled water. Animals were sacrificed $12 \mathrm{hr}$ after the last dose of diltiazem or verapamil. Then the liver was perfused in siiu with $0.9 \% \mathrm{NaCl}$ solution and homogenized with 4 volumes of $1.15 \% \mathrm{KCl}$ solution. The homogenate was centrifuged at $9,000 \mathrm{~g}$ for $20 \mathrm{~min}$. The resulting supernatant fraction was centrifuged again at $105,000 \mathrm{~g}$ for $90 \mathrm{~min}$. The pellets were washed once and suspended in $0.1 \mathrm{M}$ phosphate buffer ( $\mathrm{pH} 7.4$ ) as the microsomal fraction for determination of enzyme contents and activities.

In vivo study: Male SD rats were administered $140 \mathrm{mg} / \mathrm{kg}$ diltiazem hydrochloride, or $47.5 \mathrm{mg} / \mathrm{kg}$ verapamil hydrochloride orally, 7 times at intervals of 12 hours. AP $(50 \mathrm{mg} / \mathrm{kg})$ was administered intraperitoneally at the time the final dose of diltiazem or verapamil was given. Urine samples were collected for analysis of AP and its main metabolites until $24 \mathrm{hr}$ after AP administration and stored at $-20^{\circ} \mathrm{C}$ until assayed.

TMO $(100 \mathrm{mg} / \mathrm{kg})$ was administered orally, simultaneously with the last dose of diltiazem or verapamil. Blood samples were taken $2 \mathrm{hr}$ after the TMO dose for analysis of TMO and its only metabolite dimethadione (DMO).

Debriscquine sulphate $(\mathrm{DB} ; 5 \mathrm{mg} / \mathrm{kg}$ ) was given orally at the same time as the final dose of diltiazem or verapamil. Twenty-four hour urine samples were collected for analysis of DB and its main metabolite 4-OHDB.

Assays: The contents of microsomal cytochrome P-450 and cytochrome $b_{5}$ were deter- 
mined by the method of Omura and Sato ${ }^{1: 3)}$. Aminopyrine N-demethylase (Am-DM) activity was measured by the method of Cochin and Axelrod ${ }^{14)}$. Aniline hydroxylase (An-OH) activity was measured by the method of Imai et al. ${ }^{15)}$. Urinary concentration of AP metabolites, OHA, HMA and NorA were assayed by the modified method of Danhof et al. using $\mathrm{HPLC}^{16)}$. Serum TMO and its metabolite DMO were analyzed by gas chromatography as described by Tanaka et al. ${ }^{1 \tau}$ ). DB and 4-OHDB were determined by the method of Harrison et al. ${ }^{18)}$.

Data analysis: Data are reported as mean \pm S.E.. For AP metabolism urinary excretion of each AP metabolite is expressed as percentage of dose administered. Serum DMO/TMO ratios and urinary 4-OHDB/DB ratios were calculated for the effect of diltiazem and verapamil on TMO metabolism and DB metabolism. Statistical analysis was by Student's t-test at a 5\% significant level.

\section{Results}

Ex vivo study: Table 1 summarizes the results of activity change and the hepatic microsomal drug-oxidizing enzyme content after diltiazem and verapamil treatment.

Figure 1 shows percent changes in P-450 and $b_{5}$ after diltiazem and verapamil treatment compared to control value. Diltiazem treatment significantly increased the content of $\mathrm{P}-450$ $27.9 \%(\mathrm{p}<0.05)$ on the 1 st day, 55.7\% $(\mathrm{p}<0.01)$ on the $3 \mathrm{rd}$ day, and $60.8 \%(\mathrm{p}<0.01)$ on the 5th day compared to the control values. Content of $b_{5}$ tended to be increased by diltiazem but not significantly. Verapamil significantly increased the P-450 31.6\% on day $3(\mathrm{p}<0.01)$ and $51.3 \%$ on day $5(\mathrm{p}<0.01)$ compared to the control values. Verapamil treatment significantly increased the content of $b_{5}(45.3 \%, p<0.05)$ on day 5 .

Figure 2 shows percent change in the activity of Am-DM and $\mathrm{An}-\mathrm{OH}$ by diltiazem and verapamil. Diltiazem significantly increased Am-DM activity from day 1 to day 5 (day 1, $55.4 \%, \mathrm{p}<0.01$; day 3, 30.1\%, $\mathrm{p}<0.05$; day 5, 61.9\%, $\mathrm{p}<0.01)$. Diltiazem also increased An-OH actiivty $35.8 \%$ on day $1(\mathrm{p}<0.01)$, but $\mathrm{An}-\mathrm{OH}$ activity returned to control level on days 3 and 5. Verapamil treatment gradually increased Am-DM activity and this became significant compared to control $(47.8 \%, \mathrm{p}<0.01)$ by day 5 . An-OH activity also increased during verapamil treatment and was significant by day $5(33.8 \%, \mathrm{p}<0.01)$.

Table 1. Effect of diltiazem and verapamil on hepatic drug metabolizing enzymes in SD rat.

\begin{tabular}{|c|c|c|c|c|c|}
\hline & & \multicolumn{2}{|c|}{ Cytochrome } & \multirow{2}{*}{$\begin{array}{l}\text { Aniline } \\
\text { hydroxylase } \\
\text { (nmol/mg }\end{array}$} & \multirow{2}{*}{$\begin{array}{l}\text { Aminopyrine } \\
\text { N-demethylase } \\
\text { ein/min) }\end{array}$} \\
\hline & & $\begin{array}{l}\mathrm{P}-450 \text { (nmol } / \\
\end{array}$ & tein) ${ }^{b_{5}}$ & & \\
\hline \multirow{3}{*}{$\begin{array}{l}1 \text { day } \\
(n=4)\end{array}$} & Control & $0.74 \pm 0.04$ & $0.21 \pm 0.02$ & $0.80 \pm 0.06$ & $5.23 \pm 0.58$ \\
\hline & verapamil & $0.77 \pm 0.07$ & $0.20 \pm 0.04$ & $0.86 \pm 0.15$ & $5.70 \pm 0.80$ \\
\hline & diltiazem & $0.94 \pm 0.06 *$ & $0.21 \pm 0.03$ & $1.08 \pm 0.04 * *$ & $8.12 \pm 0.46^{* *}$ \\
\hline \multirow{3}{*}{$\begin{array}{l}3 \text { day } \\
(n=4)\end{array}$} & Control & $1.02 \pm 0.06$ & $0.35 \pm 0.03$ & $1.09 \pm 0.06$ & $6.24 \pm 0.52$ \\
\hline & verapamil & $1.35 \pm 0.07 * *$ & $0.35 \pm 0.02$ & $1.26 \pm 0.17$ & $8.47 \pm 0.51^{*}$ \\
\hline & diltiazem & $1.59 \pm 0.06^{* *}$ & $0.39 \pm 0.01$ & $1.17 \pm 0.16$ & $8.12 \pm 0.78^{*}$ \\
\hline \multirow{3}{*}{$\begin{array}{l}5 \text { day } \\
(n=4)\end{array}$} & Control & $0.70 \pm 0.07$ & $0.20 \pm 0.02$ & $1.00 \pm 0.05$ & $4.47 \pm 0.21$ \\
\hline & verapamil & $1.07 \pm 0.09 * *$ & $0.28 \pm 0.02 *$ & $1.34 \pm 0.08^{* *}$ & $6.56 \pm 0.56 * *$ \\
\hline & diltiazem & $1.13 \pm 0.02 * *$ & $0.27 \pm 0.09$ & $1.20 \pm 0.12$ & $7.18 \pm 0.07 * *$ \\
\hline
\end{tabular}

MeantS.E. ${ }^{*} \mathrm{p}<0.05, * * \mathrm{p}<0.01$. 


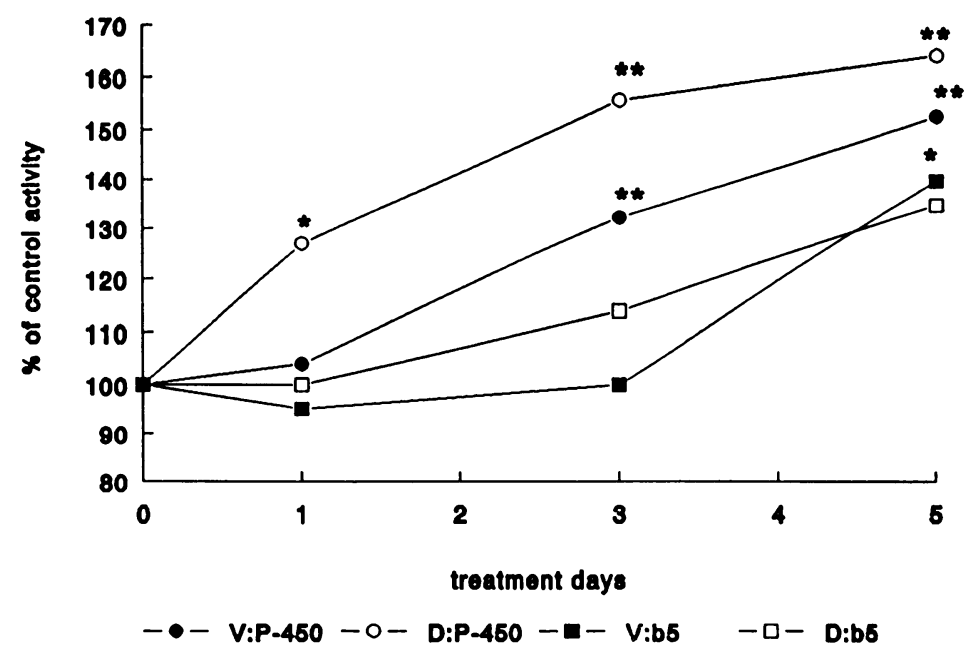

Fig. 1. Changes in the contents of cytochrome P-450 and $b_{s}$ after multiple doses of diltiazem $(140 \mathrm{mg} / \mathrm{kg})$ and verapamil $(47.5 \mathrm{mg} / \mathrm{kg})$. - - : P-450, verapamil; — $\bigcirc:$ P-450, diltiazem; - - : $b_{5}$, verapamil; $-\square-: b_{5}$, diltiazem. Drugs were administered orally every 12 hours. Values are mean \pm SE. ${ }^{*} \mathrm{p}<0.05, * * \mathrm{p}<0.01$.

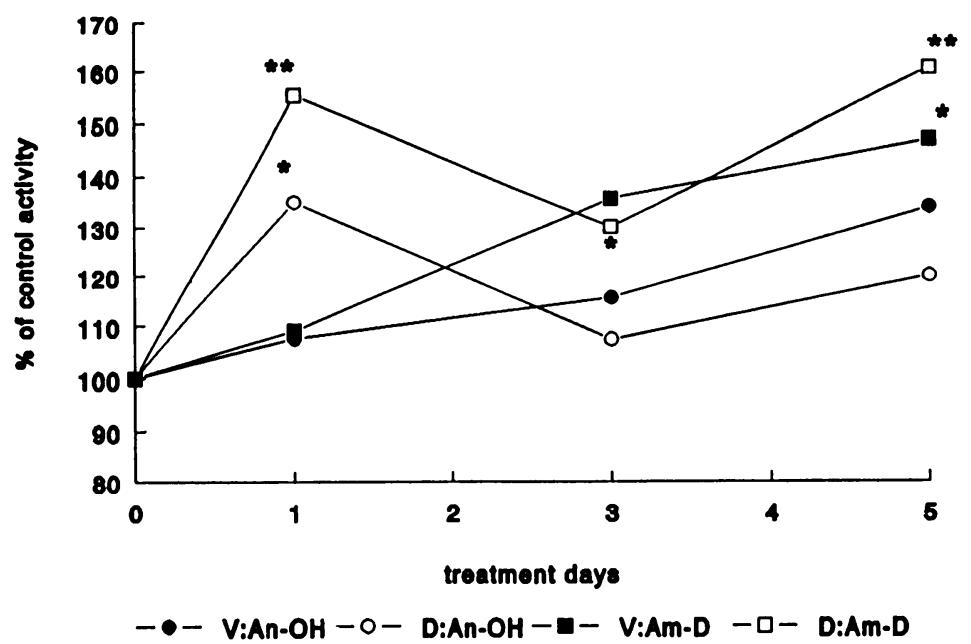

Fig. 2. Changes in the activities of aminopyrine N-demethylase (Am-D) and aniline hydroxylase $(\mathrm{An}-\mathrm{OH})$ by the treatment with diltiazem $(140 \mathrm{mg} / \mathrm{kg})$ and verapamil $(47.5$ $\mathrm{mg} / \mathrm{kg}$ ). - - - : An-OH, verapamil; -O-: An-OH, diltiazem; - - - : Am-D, verapamil; - $\square-$ : Am-D, diltiazem. Drugs were administered orally every 12 hours. ${ }^{*} \mathrm{p}<0.05,{ }^{* *} \mathrm{p}<0.01$.

In vivo study: Figure 3 shows changes in serum DMO/TMO ratios after diltiazem or verapamil treatment. Diltiazem significantly increased serum DMO/TMO ratio from 0.40 to $0.87(\mathrm{p}<0.05)$. There was no significant change in DMO/TMO ratio by verapamil treatment (mean; 0.37). Figure 4 shows the amount of AP metabolites (percent of dose) excreted into 


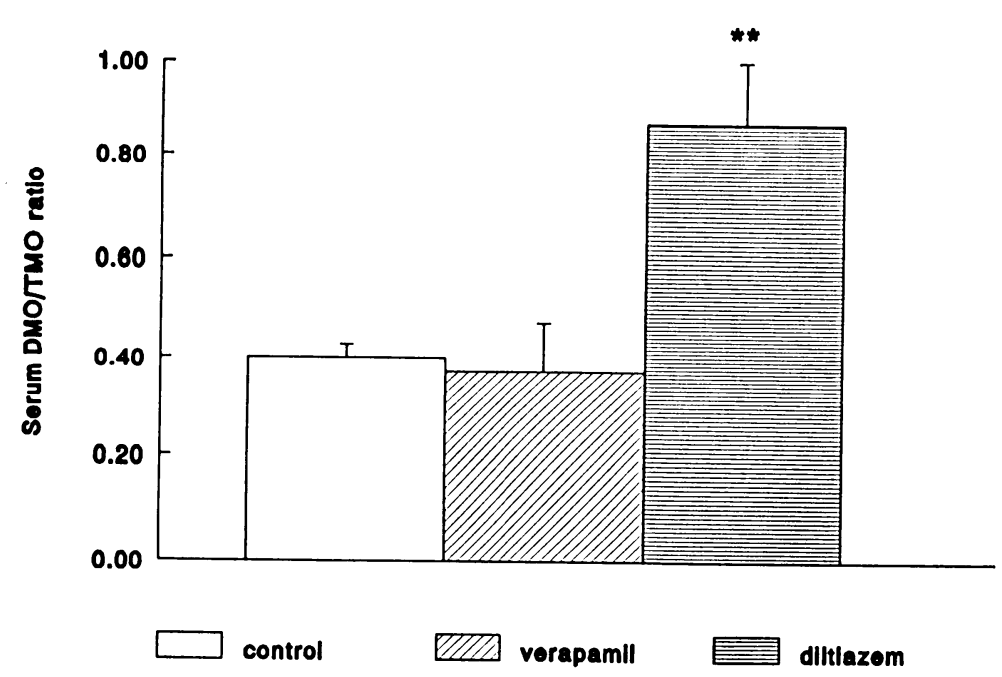

Fig. 3. Serum DMO/TMO ratios after treatment with diltiazem and verapamil for 3 days. Diltiazem $(140 \mathrm{mg} / \mathrm{kg})$ and verapamil $(47.5 \mathrm{mg} / \mathrm{kg})$ were given every 12 hours for 3 days. TMO $(100 \mathrm{mg} / \mathrm{kg})$ was administered at the same time as the last dose of drugs. Blood samples were taken at $2 \mathrm{hr}$ after TMO administration. ${ }^{* *} \mathrm{p}<0.01$.

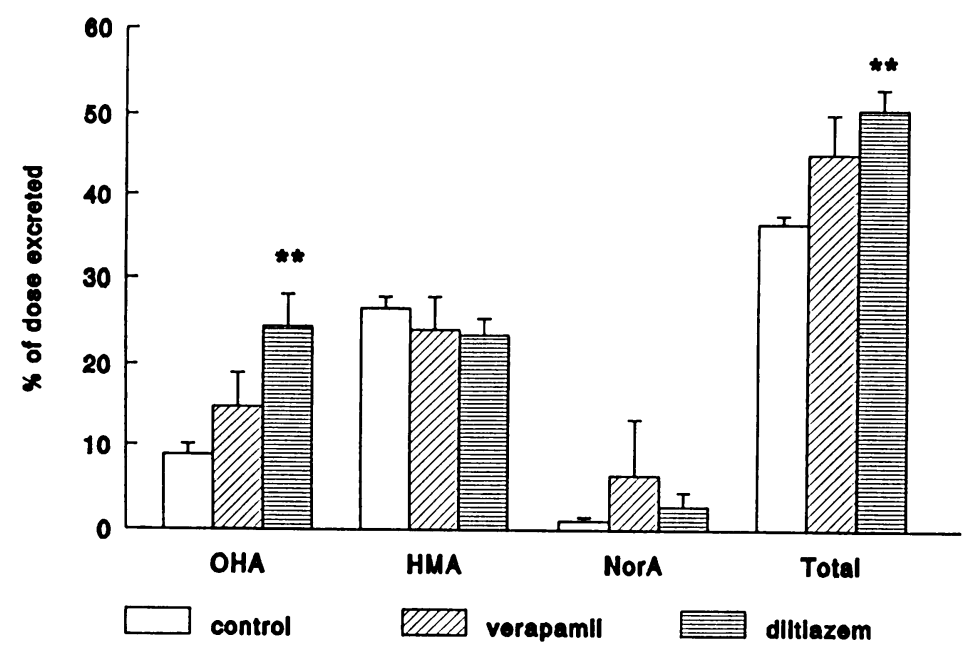

Fig. 4. Effect of diltiazem and verapamil on antipyrine metabolism. Antipyrine was administered at $50 \mathrm{mg} / \mathrm{kg}$ intraperitoneally with the last dose of drugs. Urine was collected for 24 hours for analysis of each metabolite. ${ }^{* *} \mathrm{p}<0.01$.

urine after diltiazem or verapamil administration. Diltiazem significantly increased the amount of OHA excreted into urine from $8.8 \%$ to $24.5 \% \quad(\mathrm{p}<0.01)$. No significant changes were seen in the excretion of NorA or HMA caused by diltiazem. Although verapamil tended to increase the amounts of OHA and NorA, the change was not significant for any metabolite. The DB/4-OHDB ratio was significantly increased after both diltiazem (from 0.30 to 1.83, $\mathrm{p}<0.01$ ) and verapamil (from 0.30 to $3.73, \mathrm{p}<0.05$ ) treatments (Fig. 5). 


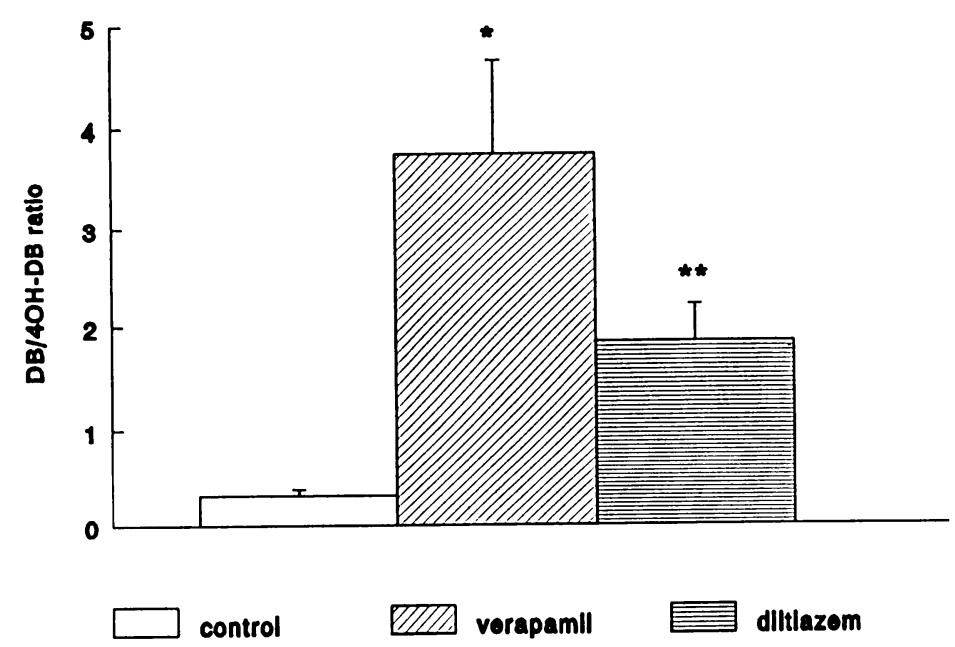

Fig. 5. Effect of diltiazem and verapamil on debrisoquine metabolism. Debrisoquine (DB) was administered orally at $5 \mathrm{mg} / \mathrm{kg}$ with the last dose of drugs. Urine was collected for 24 hours for analysis of debrisoquine and its metabolite 4-hydroxy debrisoquine (4-OHDB). ${ }^{*} \mathrm{p}<0.05,{ }^{* *} \mathrm{p}<0.01$.

\section{Discussion}

Several model drugs have been used to assess changes in hepatic drug metabolizing capacity in intact animals and man. AP is one of the most useful test drugs for monitoring hepatic mixed-function monoxygenase activity, since it is rapidly and completely absorbed from the gastrointestinal tract and distributed in total body water without binding to tissue or plasma proteins ${ }^{19)}$. AP is extensively metabolized in the liver with a low extraction ratio, and hence its clearance from plasma is independent of liver blood flow ${ }^{20)}$. AP is transformed into 3 major metabolites, OHA, HMA and NorA, by P-450 isozymes which are thought to be different from each other ${ }^{21)}$. Another model drug, TMO, is converted into only one metabolite, DMO, through $\mathrm{N}$-demethylation by $\mathrm{P}-450$ isozyme or isozymes. The serum DMO/TMO ratio has been used as an index to assess hepatic drug $\mathrm{N}$-demethylation capacity in both rats and man $^{22}$. P-450 isozyme(s) responsible for DB metabolism is(are) so called P-450dbl which differs from those involved in AP metabolism ${ }^{21)}$. Thus the combination of these 3 model drugs may give some clue for discrimination of P-450 isozymes responsible for the metabolism of other drugs.

In the present study both diltiazem and verapamil significantly increased P-450 content and Am-DM activity. Only verapamil significantly increased $b_{5}$ content and An-OH activity suggesting an increased supply of electrons from $b_{\overline{5}}$ to An-OH after verapamil treatment. Renton $^{23)}$ reported the inhibitory effect of verapamil and diltiazem on Am-DM activity using a mouse microsomal fraction in vitro. The opposite results of our study may be due to different experimental conditions (in vitro vs ex vivo), since Lan et al. also reported an increase in the activity of Am-DM after diltiazem treatment in vivo in rats ${ }^{24)}$. From the present results of in vivo study using AP as a model drug, diltiazem significantly increased the amount of OHA excreted into urine, but verapamil had no significant effect on the excreted AP metabolites. Thus verapamil seemed to have no effect on AP metabolism in 
rats in contrast to the results in humans ${ }^{9,10)}$. We have reported that diltiazem significantly decreases plasma AP clearance and formation clearance of each metabolite in healthy subjects $^{5)}$. The results of diltiazem are not the same in rats and in man.

Diltiazem significantly increased the serum DMO/TMO ratio suggesting facilitated TMO metabolism. Verapamil had no effect on the DMO/TMO ratio. Considering that diltiazem had no effect on the demethylation of AP, P-450 isozyme(s) responsible for TMO demethylation differ from those involved in AP demethylation.

Both diltiazem and verapamil significantly increased the ratio of DB/4-OHDB indicating the inhibition of DB hydroxylation. DB-hydroxylase (P-450dbl) is known to be involved in the metabolism of metoprolol, timolol, bufuralol, sparteine, flecainide, and others ${ }^{21)}$. It is well known that from a pharmaco-genetic view there are poor-metabolizers of DB in about $10 \%$ of the Caucasian population and only a few percent in Japanese ${ }^{25)}$. Present results indicated that both diltiazem and verapamil inhibited DB metabolism as well as quinine in rats ${ }^{26)}$ suggesting the possibility of producing animal models of poor-metabolism of DB in experimental conditions. In our previous study, diltiazem also inhibited DB metabolism in healthy subjects ${ }^{5)}$.

From these results, both diltiazem and verapamil induce cytochrome P-450, but have different effects on the activity of each P-450 isozyme in rats. Inhibition of the P-450 system by diltiazem and verapamil that was reported in humans, was also seen in the metabolism of $\mathrm{DB}$ in the rat.

\section{Acknowledgement}

We thank Mr. Takeyama and Ms. Chida for technical assistance throughout the study. This work was supported by Grant-in-Aid for Scientific Research No. 01570114 from the Ministry of Education, Science and Culture in Japan.

\section{References}

1) Braunwald E: Mechanism of action of calcium channel blocking drugs. $N$ Engl J Med, 307: 16181627 (1982)

2) Eichelbaum $M$ and Somogy A: Inter- and intra-subject variation in the first-pass elimination of highly cleared drugs during chronic dosing. Eur J Clin Pharmacol, 26: 47-53 (1984)

3) Tateishi T, Ohashi K, Sudo T, Sakamoto K, Toyosaki N, Hosoda S, Toyo-oka T, Kumagai Y, Sugimoto K, Fujimura A and Ebihara A: Dose dependent effect of diltiazem on the pharmacokinetics of nifedipine. J Clin Pharmacol, 29: 994-997 (1989)

4) Tateishi T, Nakashima H, Shitou T, Kumagai Y, Ohashi K, Hosoda $S$ and Ebihara A: Effect of diltiazem on the pharmacokinetics of propranolol, metoprolol and atenolol. Eur J Clin Pharmacol, 36: 67-70 (1989)

5) Sakai H, Kobayashi S, Hamada K, Akita H, Tanaka E, Uchida E and Yasuhara H: The effects of diltiazem on hepatic drug metabolizing enzymes in man using antipyrine, trimethadione and debrisoquine as model substrates. Br J Clin Pharmacol, 31: 353-355 (1991)

6) Bauer LA, Stenwall M, Horn JR, Davis R, Opheim K and Greene L: Changes in antipyrine and indocyanine green kinetics during nifedipine, verapamil and diltiazem therapy. Clin Pharmacol Ther, 40: 239-242 (1986)

7) Pederson KE, Thayssen $P$ and Klitgaart NA: Influence of verapamil on the inotropism and pharmacokinetics of digoxin. Eur J Clin Pharmacol, 25: 199-206 (1983)

8) Klein HO, Lang R, Weiss E, Di Segni E, Libhaber C, Guerro J and Kaplinsky E: The influence of verapamil on serum digoxin concentration. Circulation, 65: 998-1003 (1982)

9) Rumiantsev DO, Piotrovskii, VK, Riabokon OS, Slastnikova ID, Kokurina EV and Metelitsa VI: The effect of oral verapamil therapy on antipyrine clearance. Br J Clin Pharmacol, 22: 606-609 (1986) 
10) Bach D, Blevins R, Kerner N, Rubenfire $M$ and Edwards DJ: The effect of verapamil on antipyrine pharmacokinetics and metabolism in man. Br J Clin Pharmacol, 21: 655-659 (1986)

11) Edwards DJ, Lavoie R, Beckman H, Blevins $\mathbf{R}$ and Rubenfire $\mathbf{M}$ : The effect of coadministration of verapamil on the pharmacokinetics and metabolism of quinidine. Clin Pharmacol Ther, 41: 6873 (1987)

12) Abernethy DR, Egan JM, Dickinson TH and Carrum G: Substrate-selective inhibition by verapamil and diltiazem: Differential disposition of antipyrine and theophylline in humans. J Pharmacol Exp Ther, 244: 994-999 (1988)

13) Omura $T$ and Sato $R$ : The carbon monoxide-binding pigment of liver microsome. J Biol Chem, 239: 2370-2378 (1964)

14) Cochin J and Axelrod J: Biochemical and pharmacological changes in the rat following chronic administration of morphine, nalorphine and normorphine. J Pharmacol Exp Ther, 125: 105-110 (1959)

15) Imai $Y$, Ito A and Sato R: Evidence for biochemically different types of vesicles in the hepatic microsomal fraction. J Biochem, 60: 417-428 (1966)

16) Danhof $M$, De Groot-Van Der Vis $E$ and Breimer DD: Assay of antipyrine and its primary metabolites in plasma, saliva and urine by high-performance liquid chromatography and some preliminary results in man. Pharmacology, 18: 210-223 (1979)

17) Tanaka E, Kinoshita H, Yamamoto T, Kuroiwa $Y$ and Takabatake E: Pharmacokinetic studies of trimethadione and its metabolite in rats with chemical-induced liver injury. J Pharmacobiodyn, 4: 576-583 (1981)

18) Harrison PM, Tonkin AM, Dixon ST and McLean AJ: Determination of debrisoquine and its 4-hydroxy metabolite in urine by high-performance liquid chromatography. J Chromatogr, 374: 204-208 (1986)

19) Vesell ES: The antipyrine test in clinical pharmacology: Conceptions and misconceptions. Clin Pharmacol Ther, 26: 275-286 (1979)

20) Branch RA, Shand DG, Wilkinson GR and Nies AS: Increased clearance of antipyrine and dpropranolol after phenobarbital treatment in the monkey. J Clin Invest, 53: 1101-1107 (1974)

21) Breimer DD, Schellens JHM and Soons PA: Assessment of in vivo oxidative drug metabolizing enzyme activity in man by applying a cocktail approach. In: Microsomes and Drug Oxidations, Miners JO, Birkett DJ, Drew R, May BK and McManus ME (Eds), Taylor \& Francis, London, New York and Philadelphia, pp 232-40 (1987)

22) Kobayashi S, Tanaka E, Oguchi K, Yoshida T, Kuroiwa Y and Yasuhara H: A method for estimation of hepatic drug-metabolizing capacity: Determination of concentration of trimethadione and its metabolite in human serum. J Pharmacobiodyn, 7: 329-335 (1984)

23) Renton KW: Inhibition of hepatic microsomal drug metabolism by the calcium channel blockers diltiazem and verapamil. Biochem Pharmacol, 34: 2549-2553 (1985)

24) Lan SJ, Scanlan LM, Weinsten SH and Miqudalof BH: Induction of hepatic microsomal drugmetabolizing enzymes by calcium channel blockers in rats. Pharmacologist, 31: 174 (1989)

25) Nakamura K, Goto F, Ray WA, McAllister CB, Jacqz E, Wilkinson GR and Branch RA: Interethnic differences in genetic polymorphism of debrisoquine and mephenytoin hydroxylation between Japanese and Caucasian population. Clin Pharmacol Ther, 38: 402-408 (1985)

26) Kobayashi S, Murray S, Watson D, Sesardic D, Davies DS and Boobis A: The specificity of inhibition of debrisoquine 4-hydroxylase activity by quinidine and quinine in the rat is inverse of that in man. Biochem Pharmacol, 38: 2795-2799 (1989)

[Received January 21, 1991: Accepted February 4, 1991] 